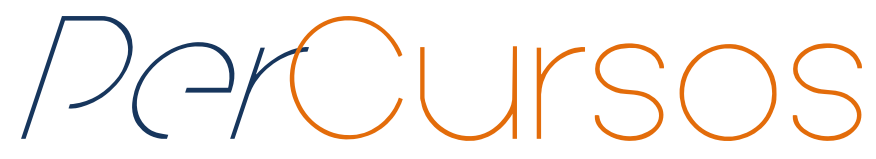

\title{
Juventude e atuação política: as ocupações em escolas públicas e novas formas de resistência e convivência nas cidades
}

\begin{abstract}
Resumo
O artigo analisa as percepções dos jovens sobre atuação política na sua participação nas ocupações das escolas públicas durante os anos de 2015 e 2016. Para tanto, foram realizadas cinco entrevistas semiestruturadas com jovens de 18 a 20 anos e que se propuseram a falar dessa experiência em 2017. Os jovens entrevistados apontam que, embora as ocupações das escolas tenham possibilitado adesão significativa dos secundaristas e da comunidade local, elas contribuíram muito mais em teor pedagógico de aprendizado político - no que se refere à convivência comunitária e uso dos espaços públicos - e menos para uma perspectiva de engajamento e continuidade da própria atuação política da juventude nas ocupações.
\end{abstract}

Palavras-chave: Juventude. Atuação Política. Escolas Públicas. Ocupação nas Escolas.

\section{Camila Nastari Fernandes}

Doutoranda em Planejamento Territorial

pela Universidade Federal do

$A B C$ - UFABC. Brasil

camilanastari@gmail.com

\section{Thaisa da Silva Ferreira}

Doutoranda em Sociologia pela Universidade Federal de Goiás - UFG. Brasil thaisafferreira@gmail.com

\section{Para citar este artigo:}

FERNANDES, Camila Nastari; FERREIRA, Thaisa da Silva. Juventude e atuação política: as ocupações em escolas públicas e novas formas de resistência e convivência nas cidades. Revista PerCursos, Florianópolis, v. 19, n.40, p. 86 - 110, maio/ago. 2018.

\section{DOI: $10.5965 / 1984724619402018086$}

http://dx.doi.org/10.5965/1984724619402018086 


\title{
Youth and political activity: occupations in public schools and new forms of resistance and coexistence in cities
}

\begin{abstract}
This article analyzes the perceptions of young people about political activity in their participation in public school occupations during the years 2015 and 2016. Five semi-structured interviews were conducted with young people between the ages of 18 and 20 who proposed to talk about this experience in 2017. The young people interviewed point out that, although school occupations have enabled significant participation by secondary school students and the local community, they have contributed much more to the pedagogical content of political learning - in terms of community living and use of public spaces - and less for a perspective of engagement and continuity of the political action of youth in occupations.
\end{abstract}

Keywords: Youth. Political Action. Public Schools. Occupation in Schools. 


\section{Introdução}

O debate sobre as ocupações nas escolas públicas pelos alunos secundaristas remete diretamente à discussão sobre juventude. O conceito juventude se faz relevante para o entendimento das diferentes formas de pensar e vivenciar o mundo, possibilitando um diálogo mais fluido e menos conflituoso com esta parcela da população. Considerando em perspectiva histórica a modernidade, o adensamento urbano, a complexidade no mundo do trabalho e as mudanças nas relações familiares, é importante compreender esta etapa da vida como algo que está em constante reconfiguração.

Otávio lanni, em um texto de 1968, chamado "O jovem radical”, aponta que nos diversos países em que se desenvolve o sistema capitalista de produção, os jovens assumem importância crescente no campo da ação política. O que significa que a juventude cada vez mais se torna rapidamente um elemento decisivo na construção de novas gerações e participações em movimentos sociais (IANNI, 1968, p. 225). Diferentemente, no processo de ocupações nas escolas públicas no Brasil, os jovens não assumem um papel de representação como "movimento social”. Entretanto, a juventude foi estruturante enquanto composição de uma força decisiva para mudança, pois possibilitou novos contornos no radicalismo político por meio de formas inéditas de atuação política.

Sendo assim, é importante atentar para uma parcela considerável de jovens brasileiros que têm atuado em diversas formas de organização e mobilização social, inclusive de maneira diferente do que foram os movimentos sociais das décadas de 1970 e 1980. De acordo com Souza (2006), é possível associar as recentes mobilizações da juventude atual com um tipo de "ativismo urbano", pois está vinculado principalmente ao espaço social, considerando o acesso a equipamentos de uso coletivo e até as condições de reprodução da força de trabalho. Trata-se de um de ativismo que tem origem em um clamor pelo direito à cidade, à luta por moradia, bem como por infraestrutura técnica e social (SOUZA, 2006, p. 280). 
O presente estudo analisa de forma qualitativa as narrativas de cinco jovens secundaristas $^{1}$ que participaram das ocupações nas escolas públicas na cidade de Goiânia entre os anos de 2015 e 2016. Tais narrativas foram recolhidas através de entrevistas semiestruturadas, que por meio de um roteiro com perguntas abertas e fechadas possibilitou aos entrevistados expor sobre o tema proposto com autonomia para manifestações espontâneas. Para tanto, elaboramos um conjunto de questões previamente definidas, porém mantendo uma perspectiva de conversa informal. Foi possível delimitar o volume das informações mantendo o foco no tema em questão.

Essa opção metodológica auxiliou na proximidade e construção de certa afetividade com o conjunto de entrevistados formado por jovens e adolescentes, além de permitir que as pesquisadoras aprofundassem questões mais complexas e delicadas. Boni e Quaresma (2005, p. 75) afirmam que as respostas espontâneas dos entrevistados e a maior liberdade que estes têm em respondê-las podem fazer surgir temas inesperados ao entrevistador que serão de grande utilidade. Os autores também apontam que este tipo de entrevista colabora muito na investigação dos aspectos afetivos e valorativos dos informantes, pois auxilia na percepção de significados pessoais de suas atitudes e comportamentos.

A partir disso, foi possível perceber a importância das dimensões da atuação política destes jovens em relação ao contexto das ocupações que ocorreram em todo o país neste período. As narrativas foram analisadas dentro da diversidade da categoria “juventude" e que será explorada no primeiro item deste artigo através dos debates e problematizações realizados nas últimas décadas pelos autores: Pierre Bourdieu, José Machado Paes e Luís Antônio Groppo.

Em seguida, o segundo item trata da importância que os entrevistados referem à atuação política, dando destaque ao fato de as ações desses jovens não terem ocorrido em um ‘vazio desorganizado' ou serem advindas de oportunismo de grupos partidários, pois a organização em torno das ocupações contou com saberes já existentes por parte

\footnotetext{
${ }^{1}$ Foram utilizadas entrevistas de três jovens mulheres e dois jovens homens que participaram ativamente nas ocupações das escolas de Goiânia em 2015/2016. Os nomes utilizados para identificar os cinco jovens são fictícios.
} 
de alguns secundaristas. Muitos jovens já estavam envolvidos com pequenos grupos coletivos e partidários antes das ações de ocupações começarem. Para tanto, foi traçado um breve histórico dos protestos juvenis ocorridos no Brasil no final da década de 1990 até a data das primeiras ocupações em 2015. O objetivo é situar o leitor sobre os processos políticos, sociais e econômicos que os secundaristas vivenciaram direta e indiretamente nessas últimas décadas, tendo como objeto de disputa central o espaço público que constitui a escola e todo seu entorno, conforme Lefebvre (2001) ressalta a apropriação dos espaços pelos cidadãos e a busca pelo “direito à cidade”.

No terceiro item são descritas as narrativas dos jovens entrevistados e as mudanças na forma de atuação política considerando que as ações dos secundaristas se organizaram e se desenvolveram sem a participação dos movimentos sociais tradicionais, o que as constitui como elemento inovador nas práticas de ações políticas. São abordadas as questões acerca do "aprendizado" político mencionado nas entrevistas e que foi decorrente do processo de ocupação das escolas. Paralelamente, descreve-se a violência policial em sua potência. E, por fim, a questão da não continuidade das ações comunitárias e suas consequências sociais e individuais para os jovens envolvidos.

O texto apresenta um convite à reflexão sobre de que maneira os jovens secundaristas demonstram suas perspectivas no liame das atuações políticas por meio das ocupações das escolas, em questionamento direto aos projetos de privatização do ensino público. As narrativas de cinco jovens que atuaram no movimento conduzem a observações relevantes sobre as possibilidades e as consequências dessas ocupações.

\section{O conceito de juventude e suas especificidades}

Há uma diversidade bastante considerável sobre o conceito de juventude nos estudos sociológicos. $\mathrm{O}$ amadurecimento dos indivíduos não segue um padrão universal e não pode ser tomado como um processo único e linear compartilhado igualmente por todos aqueles que têm determinada idade. As formas como são vividos os diferentes momentos da vida e quanto tempo eles duram, podem variar conforme contextos e circunstâncias diversas. Por isso, é tão importante ressaltar que não se trata apenas de 
uma juventude, mas sim de juventudes no plural, conforme suas variadas significações, valorações e contextos sociais (BOURDIEU, 2003; PAIS, 1990; GROPPO, 2017).

Os marcos sociais definidores das diferentes fases da vida em sociedade não são fixos e estão em constante mudança, de forma que a transição entre essas fases pode ser localizada em variados momentos, de acordo com os diferentes indivíduos e os distintos contextos culturais e econômicos em que estão inseridos.

Nos estudos da sociologia, a noção de juventude somente adquiriu certa consistência conceitual a partir do momento - entre a infância e a idade adulta - em que começou a se verificar o prolongamento dos tempos de passagem entre a infância e a vida adulta que hoje em dia mais caracterizam a juventude (PAIS, 1990, p. 148). Este prolongamento foi fortemente influenciado pela revolução industrial e é concomitante ao surgimento do ensino escolar. Havia, por um lado, a necessidade de uma demanda maior de indivíduos no mercado de trabalho, principalmente nos países europeus que já viviam o período pré-capitalista e início da industrialização. E, por outro lado, havia também o início do processo de desenvolvimento institucional-formal da educação. O que Pais (1990) descreve como a separação entre uma juventude que vai à escola e uma outra juventude que irá imediatamente para o mercado de trabalho, a depender do padrão socioeconômico familiar.

Nos séculos XIX e XX, com a presença da legislação sobre o trabalho infantil, o aumento das casas de correção para crianças e jovens e outras medidas de segurança pública, bem como com as mudanças de comportamento da família contemporânea e o aumento da dependência dos jovens em relação às suas famílias de origem, a categoria de juventude passou a ser um importante objeto de estudo das mais diversas áreas do conhecimento, como por exemplo, psicologia, medicina, direito e também da sociologia.

No campo da pesquisa sociológica, os estudos sobre juventude foram muito influenciados pela Escola de Chicago, principalmente a partir dos anos 1920. Nesse período, nos EUA, a questão dos conflitos urbanos nas grandes cidades era um tema recorrente, considerando o vertiginoso aumento populacional, consequência de 
inúmeros processos migratórios, assim como o crescimento da pobreza, marginalidade e o surgimento de gangues urbanas.

A concepção tradicional da sociologia sobre juventude, de acordo com GROPPO (2017, p. 35-36), baseia-se sobretudo nas teorias estrutural-funcionalistas, visto que contribuíram muito mais para o campo com suas descobertas empíricas -- a partir da perspectiva micro dos pesquisadores da Escola de Chicago, presente na obra de Frederic Thrasher (1964) e William Foote Whyte, por exemplo (2005) -- do que o desenvolvimento de argumentos teóricos explicativos defendidos na perspectiva macrossociológica de Talcott Parson (1968).

Para estes autores, os jovens eram compreendidos por meio de uma perspectiva psicológica de 'desorganização social'. Ideia que esteve presente nos primeiros anos das pesquisas da Escola de Chicago e que deu início à boa parte do conhecimento científico na área de juventude.

Frederic Thrasher escreveu um dos mais importantes trabalhos sobre juventude, delinquência e gangues juvenis. Sua pesquisa iniciou e influenciou os primeiros estudos em 1927, na cidade de Chicago, nos EUA. O autor foi pioneiro ao retratar como os jovens se comportavam e ocupavam os espaços públicos, dando sequência a muitas pesquisas sobre juventude e delinquência em outros países.

Através de outra perspectiva teórica e metodológica, Pierre Bourdieu (2003) afirma que "a juventude é só uma palavra" e entende que este grupo específico é construído socialmente, o que se dá na luta entre os jovens e os mais velhos. Para o autor, as classificações por idade, assim como, por sexo e classe social acabam sempre por impor limites e produzir uma ordem em que cada um deve se manter, sabendo seu lugar. Tratando-se, portanto, de uma questão de poder ou de uma forma de divisão do poder.

A ideia de juventude oposta à velhice não diz respeito apenas à idade biológica de cada um desses grupos, ela é uma condição social que orienta determinadas faixas etárias. A idade biológica refere-se muito mais aos conflitos que essa convivência apresenta nas sociedades modernas. Nesse sentido, a não compreensão dos atos juvenis 
por parte dos adultos está relacionada aos conflitos de gerações a partir das diferenças de pensamentos desses dois grupos etários, como também a perspectiva de vida entre os jovens e os mais velhos. Considerando assim, o fato de que a velhice não deixa de ser um declínio social e, consequentemente, uma perda de poder social para os mais velhos (BOURDIEU, 2003, p. 159).

Além das diferenças geracionais apresentadas nas diferenças de idade e da divisão do poder, de acordo com Bourdieu (2003), é importante considerar a juventude nas suas diferentes formas de vivenciá-la. O autor aponta que se comparássemos as condições de vida, o mercado de trabalho e a organização do cotidiano dos jovens que já trabalham com aqueles que não trabalham ou que nunca trabalharam, embora tenham a mesma idade biológica, já seria possível distinguir dois tipos de juventude. E, esses seriam apenas dois exemplos extremos de possibilidades oferecidas aos jovens em relação a tantos exemplos das diferentes formas de vivenciar a chamada juventude (BOURDIEU, 2003, p. 154).

Historicamente, foi a partir dos ambientes de ensino (escolas primárias, secundárias e universitárias), que constituem os espaços mais importantes no processo de socialização, interação e aprendizagem, de uso exclusivo dos jovens, que se criaram (e institucionalizaram) as condições para a legitimação de um tempo específico no ciclo de vida, não produtivo, principalmente do ponto de vista do capital econômico, para a preparação da vida adulta. Esse tempo específico, não produtivo e de preparação para vida adulta passa a ser a chamado "juventude".

Para José Machado Pais (1990), tais ambientes e principalmente o escolar, legitimam a ideia de uma idade que justifica o período de juventude. Entretanto, não só a escola se tornou um espaço de sociabilidade desse grupo nomeado jovem, como também os espaços públicos (as ruas, os parques, as praças e outros tantos) foram ocupados por eles. Até porque a escola, desde seu início, não possibilitava acesso universal e, nesse sentido, os estudos da Escola de Chicago tiveram grande contribuição para pesquisas sobre uma parte da realidade juvenil de uma determinada época e espaço social. 
Assim, podemos afirmar que o período da vida de um indivíduo identificado como jovem é um período de preparação entre o intervalo existente entre infância e o início da vida adulta. O que torna o jovem um adulto é a chegada da chamada "responsabilidade". Bourdieu (2003) aponta que ser jovem é poder ter uma "irresponsabilidade provisória". Ao contrário dessa situação provisória, o adulto é considerado responsável, porque responde a um conjunto determinado de obrigações e de afazeres.

Sendo assim, Groppo (2017, p. 10) aponta que a juventude deve saber negar-se, pois ela se destina a esvaziar-se na maturidade. Isto é, a não "maturidade" é a juventude, entretanto, não necessariamente os adultos irão cumprir essa ideia de maturidade, mas são eles, os adultos, a serem chamados e cobrados de forma diferente dos jovens para cumprir determinadas ações e afazeres com maturidade. Por outro lado, é possível perceber que em diversas relações familiares são os filhos que demonstram maior discernimento em relação aos seus pais ou seus responsáveis, ou seja, são eles muitas vezes (a depender da situação de determinadas famílias) que tomam decisões e fazem as escolhas mais difíceis. O que leva à seguinte reflexão: o que de fato seria "agir com maturidade"? Seria uma atitude esperada somente para os indivíduos de faixa etária adulta?

De qualquer maneira e em concordância com o autor, serão diversos marcadores (sociais, culturais e econômicos principalmente) de diferenças que permitirão ao indivíduo mudar de status - da posição social intermediária juvenil à posição privilegiada da maturidade (GROPPO, 2017, p. 14). Entende-se, assim, que a juventude é um processo e sendo um processo importa saber como determinados grupos de jovens passam por ele. No caso dos entrevistados no presente estudo, vamos tentar compreender o que significou para eles a sua participação (em conjunto com a população local) nas ocupações das escolas públicas na cidade de Goiânia, entre os anos de 2015 e 2016.

\section{Juventude e atuação política: a cidade em disputa}

A sociedade, para além de um aglomerado de diferentes indivíduos, é formada pela disputa do espaço público. Para disputar esses espaços, que são por excelência 
espaços de interesses, são necessários alguns requisitos. O que Bourdieu (2013) vai chamar de 'economia dos bens simbólicos'. Historicamente, as diferentes gerações sociais, crianças, jovens, adultos e idosos vão recorrer às suas economias (bens simbólicos) sejam elas sociais, culturais ou econômicas, para poder acessar e ter legitimidade nos espaços pretendidos e ocupados. A sociedade é também formada por uma hierarquia geracional, isto é, os adultos apresentam um maior poder de decisão sobre as crianças, sobre os jovens e também sobre os idosos.

É nesse aspecto que se dá importância às ocupações juvenis nas escolas públicas, pois apontam para uma forma de reação dos mais jovens em detrimento das decisões tomadas pelos adultos. Elas representam um enfrentamento a essa lógica, indicando questionamentos levantados pelos jovens para com a sociedade, como: que cidade queremos? Tal questão, segundo os jovens entrevistados, deveria ser debatida de forma coletiva e horizontal. Nessa perspectiva, Harvey (2012) aponta que;

A questão de que tipo de cidade queremos não pode ser divorciada do tipo de laços sociais, relação com a natureza, estilos de vida, tecnologias e valores estéticos desejamos. O direito à cidade está muito longe da liberdade individual de acesso a recursos urbanos: é o direito de mudar a nós mesmos pela mudança da cidade. Além disso, é um direito comum antes de individual já que esta transformação depende inevitavelmente do exercício de um poder coletivo de moldar o processo de urbanização. A liberdade de construir e reconstruir a cidade e a nós mesmos é, como procuro argumentar, um dos mais preciosos e negligenciados direitos. humano (HARVEY, 2012, p. 74)

Sendo assim, esses jovens demonstraram que o uso e a ocupação das escolas poderia ser em favor de todas as pessoas, a partir das demandas da própria população. Conforme colocado pelo autor, um direito comum aos habitantes e que enaltece a ideia de direito coletivo à cidade, anterior ao direito individual ou de propriedade e que se realiza mediante a atuação coletiva envolvendo os mais diferentes segmentos, grupos etários, classes, gêneros, etnias e grupos sociais. 
Anterior às ações de ocupação das escolas públicas ocorridas no Brasil em 2015, é importante lembrar que as manifestações juvenis de $1968^{2}$ demonstraram como isso pode ocorrer a partir da atuação política dos mais jovens quando estes estão em desacordo com as ordens vigentes do "mundo adulto". Nessa ocasião, a juventude inverteu a ordem hierárquica e colocou o mundo dos adultos (aparentemente equilibrado) em desequilíbrio. Contudo, essas manifestações não ocorreram e não ocorrem de um dia para outro, é preciso problematizar o discurso de que esses "levantes" juvenis sucedem repentinamente, de forma desorganizada, sem propostas e que são simplesmente protestos advindos de interesses de grupos políticos ou partidários ${ }^{3}$.

Se o ano de 2013 ficou marcado pelas mobilizações do passe livre, a memória dos jovens nos leva para as manifestações dos caras pintadas em 1992 e também para revolta do Buzu, ocorrida em Salvador, no ano de 2003. Essa última deu início a um levante nacional que questionava a dificuldade de mobilidade urbana dos jovens das diversas cidades do Brasil e o aumento da tarifa do ônibus. Tal movimento ficou conhecido como um dos mais importantes levantes juvenis de Salvador e foi a partir dele que se iniciou outro movimento que ficou conhecido como revolta da catraca, em 2004, na cidade de Florianópolis, no estado de Santa Catarina. Esse último fomentou um movimento ainda maior, conhecido como o Passe livre e que veio à tona durante o Fórum Mundial Social, ocorrido em Porto Alegre, no Rio Grande do Sul, em 2005.

Ainda que esses breves exemplos de manifestações juvenis não se conectem em tempo e espaço, eles apontam para questões de: atuação política, apropriação e mobilidade urbana para essa parcela da população. Percebe-se que o acesso e o uso dos espaços públicos foram os principais temas dos protestos juvenis nesta última década. Caldeira (2014) aponta que:

\footnotetext{
${ }^{2}$ Obviamente outras manifestações juvenis foram importantes, internacional e nacionalmente, entretanto, por falta de espaço, não falaremos dessas manifestações neste artigo.

3 Segundo o corpo editorial do jornal Estado de São Paulo apontou na reportagem sobre as ocupações. Acessado em 16/02/2018 e disponível em: <http://opiniao.estadao.com.br/noticias/geral,a-banalizacao-dasocupacoes, $10000081403>$.
} 
Foram protestos que expressaram o desejo de circular e de fazer isso com mais qualidade. O lema do Movimento Passe Livre é o mesmo que inspira várias das produções culturais periféricas e os movimentos de seus participantes (...) Tanto os protestos de junho como os rolezinhos usaram a mídia social para se organizar e ignoraram completamente as formas instituídas de representação e organização política. Ambos foram protagonizados por jovens e têm suas raízes no seu cotidiano, em uma cidade estruturada para segregar e reproduzir desigualdades. Tanto uns como outros aumentaram sua amplitude e visibilidade no momento em que foram reprimidos pela polícia. Ambos contestam autoridades constituídas e modos de regulação e separação preexistentes. (CALDEIRA, 2104, p. 19)

É importante lembrar que essas movimentações juvenis foram gestadas no decorrer de uma década que contou com acontecimentos nacionais e internacionais bastante relevantes para o país, como por exemplo: a Copa do Mundo de Futebol, em 2014, e os Jogos Olímpicos, em 2016, ambos no Brasil. Foi nesse mesmo período que ocorreram outras diversas manifestações sociais, como as greves realizadas por setores trabalhistas em todo o país, protestos de coletivos em cidades grandes e pequenas, abalos da crise econômica mundial no Brasil e, consequentemente, cortes nos gastos públicos. Foi também nesse período que ocorreu a destituição da presidenta eleita Dilma Rousseff, em forma de golpe de Estado em 2016. Em paralelo, por parte dos jovens, cresciam questionamentos em relação ao silêncio ou certa letargia dos movimentos sociais tradicionais, que supostamente eram de uma conjuntura política favorável aos últimos governos de presidência da República pelo Partido dos Trabalhadores (governos Lula e Dilma).

Foi também durante o ano de 2014 que se fomentaram, dentro dos poderes nacionais executivo e legislativo, discussões políticas para implementação de novas táticas de cerceamento social. Elas apontavam para ações de contenção e punição de manifestações públicas coletivas que cresciam naquele momento devido às contestações sobre encaminhamentos públicos na preparação de grandes eventos (como a Copa do Mundo de Futebol e as Olimpíadas) em grandes cidades do país. Acirradas discussões 
ocorreram no Senado para endurecer a legislação, como a chamada "Lei antiterrorismo", que desembocou na aprovação da Lei Federal $n^{\circ} 13.260 / 16^{4}$ e que é um exemplo dessas novas táticas.

Por outro lado, para além dos grandes eventos com promessas de ganhos econômicos, alguns governos propuseram reformular aspectos na pasta da educação consagrados na Constituição Federal de 1988. A proposta do governador Geraldo Alckmin, de privatização das escolas públicas do Estado de São Paulo, um ano após a Copa no Brasil foi uma decisão que fez com que os profissionais da área da educação, os coletivos e os jovens organizados politicamente se colocassem em alerta. Em 2015, com a PEC n 241 ou "PEC 55", como ficou conhecida popularmente, foi o gatilho para que esses coletivos juvenis ocupassem os espaços públicos (ruas e escolas) nos demais estados do país, como Ceará, Goiás, Paraná e Rio de Janeiro, de forma mais incisiva.

Sendo assim, no ano de 2015, muitos coletivos já estavam bastante organizados e conectados com os acontecimentos nacionais e internacionais. Nos depoimentos recolhidos, os entrevistados apontam que utilizaram táticas apreendidas de um manual de jovens chilenos que atuaram na "Revolta dos Pinguins", para iniciar as ocupações das escolas públicas. Esse movimento, iniciado no Chile em 2011, ocorreu em mais de 700 escolas, ocupadas pelo Movimento Secundarista Chileno, que lutava por direitos no transporte público e melhorias na rede pública de educação. A revolta em questão foi assim intitulada remetendo-se aos uniformes utilizados pelas crianças e jovens que protestaram nas escolas e nas ruas.

Nesse sentido, fica evidenciado que as manifestações políticas promovidas pela juventude não sucedem em um vazio. Os movimentos juvenis têm sua maneira específica de ser e de acontecer, de tal forma que as causas e disputas colocadas chegam de forma inteligíveis para a geração de adultos, para os veículos institucionais de imprensa e também para a atuação governamental. O que por sua vez, encontram dificuldade em dar

\footnotetext{
${ }^{4}$ Lei Federal n 13.260/16 que ficou conhecida como "antiterrorista". Ela dispõe sobre o inciso XLIII do art. 50 da Constituição Federal, disciplinando o terrorismo, tratando de disposições investigatórias e processuais e reformulando o conceito de organização terrorista; e altera as Leis nos 7.960, de 21 de dezembro de 1989, e 12.850, de 2 de agosto de 2013.
} 
legitimidade para as pautas levantadas e coerentes com as discussões de direitos básicos e fundamentais, como acesso à educação de qualidade e acesso à cidade.

As movimentações estudantis, através das ocupações nas escolas, carregam outras camadas de significados e que vão ao encontro do que Lefebvre (2001) conceitua como a apropriação do espaço pelos indivíduos, na sua obra "O Direito à Cidade”. O autor descreve que, para além da ideia de propriedade, é necessário dar importância também ao uso do espaço urbano, em especial os espaços públicos que podem e devem ser apropriados de forma coletiva pelos citadinos. Essa concepção foi direcionada para a classe trabalhadora enquanto um conjunto de atores relevante nos conflitos urbanos, mas, pode ser associada às ações promovidas por esses jovens contemporâneos que também se manifestam por direitos sociais e se expressaram através do uso concreto e simbólico das escolas públicas.

As ocupações foram tentativas de disputa pela cidade por parte da juventude que ousou reinventar sua existência e permanência nos espaços públicos. Marta, uma das jovens entrevistadas observa:

Nós não concordamos com a mercantilização e a privatização do ensino público como solução da falta de investimento histórico, por parte dos governos e por isso ocupamos as escolas (...). A escola deve continuar pública e ser de qualidade (...) assim como outros serviços públicos.

Para esses jovens, as ocupações representaram um caminho na busca do direito à cidade, se tornando assim um ato significativo para a efetivação de outros direitos sociais básicos como: educação, moradia, saúde, cultura, mobilidade e lazer para essa parcela da população. Os processos de formação dos jovens como sujeitos de direitos e de desenvolvimento pleno da cidadania estão relacionados à vivência dos territórios urbanos com liberdade, segurança e garantia de acesso a serviços e equipamentos públicos.

Tanto o direito à cidade, quanto a circulação no espaço público urbano quase sempre foram mais experimentados por determinados grupos, segundo Caldeira (2014): 
Desde os tempos de Baudelaire, vagar pela cidade foi mais para uns homens, ricos, dândis — do que para outros — mulheres, pobres, negros, jovens. O controle dos movimentos em público nunca deixou de estar no cerne da preocupação dos governantes e das suas tecnologias de segurança. Desde os primórdios das cidades modernas, circular por circular, andar em grupos (sobretudo de homens jovens), dar uma volta, ou dar um rolê, são atividades que acabam sendo escrutinadas e, no limite, criminalizadas, a não ser que os protagonistas (em geral homens) pertençam a grupos privilegiados. (CALDEIRA, 2014, p. 13)

A autora evidencia que o acesso à cidade, em especial aos espaços públicos, como também a apropriação nos moldes colocados por Lefebvre (2001) são quase que restritos para determinada parcela da população. Nesse sentido, acessar e usufruir desses espaços passa necessariamente por alguma disputa. E no caso das ocupações, passa também por reivindicações coletivas tanto concretas quanto simbólicas.

\section{Mudanças nas formas de atuação política: o aprendizado político, a violência}

\section{policial e o adoecimento dos jovens ativistas}

Os jovens participantes das ocupações que foram entrevistados neste estudo afirmam ser adeptos de uma ideia de movimento independente, apartidário e com práticas horizontais. Tal concepção aparece de forma distinta a das manifestações sociais realizadas pelos jovens entre as décadas de 1970 e 1980 no Brasil. Primeiramente, por representar uma resposta de não aceitação às formas de atuação de grupos partidários tradicionais, e também por representar uma mescla de ações políticas com orientação de esquerda, embora não partidárias, entre ativistas anarquistas e feministas. Sobre isso, Lúcia comenta em uma das entrevistas que:

Muitos alunos que participaram (das ocupações) já faziam parte do grêmio da escola, mas também tinha uma galera que nunca tinha ouvido falar em nada disso. Tinha também um povo que já sabia das manifestações desde 2013, mas só de ouvir falar. E tinha os grupos de meninas feministas que foi massa, mas você vê, essa galera não ficava apontando partido não. 
Acrescentando, Saulo aponta:

É (...) tinha a participação dos alunos, mas também teve o pessoal que já era envolvido com os partidos, como te falei. Eles influenciaram sim, para o bem e para o mal, né? Porque eles às vezes queriam colocar as coisas tudo do jeito deles. Mas isso não foi a ponto de atrapalhar o que foi o movimento dos secundaristas. Porque a gente usava isso a nosso favor e não para disputas de partido.

Ainda que sejam bastante presentes no discurso e nas ações dos estudantes algumas ideias advindas de partidos políticos, os entrevistados alegaram que as ocupações inicialmente foram promovidas por secundaristas que apresentavam pouca ou nenhuma experiência política. Dentre os cinco estudantes entrevistados, três mencionaram não estarem envolvidos com partidos no momento da ocupação e todos disseram ter participado ativamente do grêmio estudantil em suas escolas. Após o término do processo de ocupações das escolas, três dos entrevistados mencionaram que passaram a participar ativamente de grupos e partidos políticos ${ }^{5}$.

No decorrer das ocupações das escolas, outros grupos aderiram e participaram ativamente das ações em conjunto e apoiando os estudantes, entre eles: grupos ligados à esquerda, coletivos anarquistas e feministas ${ }^{6}$, assim como estudantes do ensino superior das universidades públicas. Entretanto, essa convergência com diversos segmentos não ocorreu de forma harmoniosa conforme explicação adiante.

Os entrevistados apontaram que desde as manifestações de 2003 (revolta do Buzu), ganhou força uma ideia de participação por meio de coletivos com direcionamento e características de horizontalidade. Porém, esse pressuposto foi divulgado e interpretado pelos grandes meios de comunicação, bem como pelos agentes do Estado (em especial de segurança pública como a polícia militar), como algo desorganizado, pois não localizaram uma liderança ou porta-voz desses coletivos. Algo similar ocorreu também nas ocupações estudantis; a falta de uma liderança explícita e não identificação

\footnotetext{
${ }^{5}$ União da Juventude Comunista - UJC e Partido Comunista do Brasil - PCdoB.

6 Partido Socialismo e Liberdade (PSOL), Partido Comunista do Brasil (PCdoB), Levante Popular da Juventude (LPJ), Movimento Passe Livre (MPL) entre outros.
} 
de um canal de comunicação e diálogo com os jovens. Esse foi um elemento que reforçou certo ineditismo na tática adotada por eles, mas que acirrou o embate com as instituições de segurança e agentes de comunicação.

Nas ocupações, foram criadas diversas comissões dentro de cada escola para organizar e dividir as tarefas diárias entre os participantes. Um deles, Otávio, explica que:

Em todas as escolas que ocupamos houve mobilização dos alunos, todo mundo queria mudar aquilo. Tivemos ajuda de algumas professoras e até mesmo de alguns pais de alunos, a comunidade participou também, mas o mais importante é que não tinha hierarquia, tudo era dividido e feito em grupo, sabe? Tinha uma vontade em aprender e de mudar de todos. Claro que isso não foi assim, tranquilo, sem brigas e discussões, mas tudo foi decidido em grupo. Tínhamos atividades todos os dias.

Cronogramas de atividades foram feitos com nomes, datas e atividades para cada ocupante, o que ocasionou conflitos de gênero ${ }^{7}$, mas também serviu para iniciar conversas e mediações de divergências que nunca haviam sido problematizadas tanto pelos alunos quanto pela comunidade. As atividades a serem feitas nos espaços escolares eram discutidas e decididas por assembleias ou reuniões. E neste sentido, a não existência de líderes motivou os diversos atores ali presentes a terem autonomia e poder de decisão.

Uma das escolas ocupadas em Goiânia era uma "escola de lata" e nela a comissão de ocupação decidiu por fazer reformas na escola. Foram promovidas atividades entre os alunos para: capinar, retirar lixo e entulho do entorno, separar e retirar mobiliário quebrado da área de esportes. Em conjunto com os moradores, foi sugerido o plantio de uma horta comunitária que foi iniciada e mantida durante o período da ocupação. Lúcia comenta sobre a sua experiência nessa escola:

E você vê a mídia só falando que a gente estava quebrando, depredando, roubando tudo (risos). A ocupação foi a vez que eu mais vi gente do meu

\footnotetext{
${ }^{7}$ As entrevistadas apontaram para uma importante presença feminina nas ocupações e essa questão merece um estudo mais aprofundado. Contudo, não teríamos espaço nesse texto para tal debate.
} 
bairro reunida com pessoas de outros bairros para fazer alguma coisa que presta. Cê pirá ${ }^{8}$ ?

Em outra escola, o muro foi reformado pelos pais dos alunos junto com os estudantes e ela esteve aberta para atividades culturais em todo o período da ocupação. Os moradores do bairro também fizeram a festa de natal dentro da escola para que os estudantes da ocupação pudessem participar.

Fatos como esses foram conferidos em outras ocupações estudantis por todo o território nacional, inclusive com o apoio de personalidades artísticas $^{9}$ e a promoção de eventos culturais. Nesse sentido, verificou-se que o espaço da escola e as atividades promovidas pelos ocupantes, em parceria com diferentes atores sociais, possibilitaram um ambiente pedagógico de aprendizado político e social. Segundo os entrevistados, foi possível constatar uma aproximação concreta e um maior entendimento entre a população e a escola como equipamento público, tanto de direito como de uso, através de uma vivência comunitária e da troca de saberes.

Atividades como: rodas de conversas com temas dos mais diversificados, discussões sobre segurança pública, saúde e hortas comunitárias fizeram parte das atividades desses jovens e adultos. Grande parte da população dos bairros que tiveram suas escolas ocupadas nunca tinham vivenciado essas possibilidades de discussão e participação no seu entorno da vizinhança. As ocupações em certa medida serviram como extensão da casa até a rua, conformando um espaço de trocas e vivências que antes não haviam sido experimentadas pela população da cidade de Goiânia.

Os secundaristas entrevistados afirmam que a atuação contou com movimentos propositivos e entendidos como revolucionários em essência. O discurso colocado como contrário a essa afirmação, sobre tais movimentos como desorganizados, ou jovens sem propostas de melhoria para as escolas e, principalmente, como lócus de vandalismos, apontavam para uma negação da autonomia e do protagonismo desses jovens, descaracterizando o caráter revolucionário da atuação juvenil daquela ocasião.

\footnotetext{
${ }^{8}$ Essa expressão é bastante comum entre o os jovens goianos e significa "você acredita?".

${ }^{9}$ Conforme notícia de maio de 2016: "Marisa Monte e Leoni fazem show de graça em colégio ocupado no Leblon.” Disponível em: <http://glo.bo/1UtO3Qy>. Acessado em: março de 2018.
} 
Através do movimento das ocupações escolares foi possível também evidenciar a situação precária de suas estruturas físicas, como deterioração, falta de manutenção, vazamentos, rachaduras, infiltrações e falta de mobiliário básico (armários para professores e carteiras na sala de aula). Segundo os jovens entrevistados, foram mais de 1200 escolas ocupadas em todo o país. Em Goiás, foram 28 escolas ocupadas, que contaram com o apoio dos estudantes universitários da Universidade Federal de Goiás e com mais 22 faculdades e institutos ocupados em solidariedade aos secundaristas.

Outra questão bastante mencionada pelos jovens entrevistados foi sobre a violência sofrida por parte da Polícia Militar. Diversas denúncias foram relatadas ao Ministério Público sobre a entrada de policiais militares nas escolas ocupadas, durante a noite, sem mandato judicial, assim como diversos espancamentos nos atos públicos e nas manifestações ocorridas naquela ocasião. Os jovens relataram que já no começo de 2015, quando os secundaristas tentaram dialogar com governo estadual sobre a questão da privatização das escolas, o secretário da pasta de desenvolvimento chamou a tropa de choque e dezenas de pessoas ficaram feridas, e pelo menos trinta foram detidas, conforme descreveu Otávio:

Fiquei mais de dois meses nas ocupações, organizando as ocupações em várias escolas, no Robinho (escola) foi tenso. Mas não foi lá não, foi em outra escola, estava com poucos alunos e tinha pouco apoio dos professores e dos pais, aí a polícia militar entrou e me tirou para fora e me bateu na rua. Éramos uns cinco que estávamos segurando a ocupação; apanhamos de pau na rua. Aí no outro dia a ocupação aumentou, rolou advogado, veio mais gente ocupar com o pessoal que já estava lá. Mas a polícia militar ficava de ronda, tipo eles sabiam as escolas com menos gente, aí entravam, entraram até de madrugada; era tenso.

Os secundaristas que fizeram as ocupações no estado de Goiás ainda sofreram com pedidos de reintegração de posse das escolas. A decisão foi tomada pelo desembargador Geraldo Gonçalves da Costa que, na ocasião, alegou que "A ocupação causa prejuízos à comunidade estudantil", e disse ainda em reportagem que "Prejudica a renovação de matrícula de 16.783 alunos, além de novatos e formandos aprovados no 
Enem e que necessitam de diplomas de conclusão de curso para realizar matrícula em universidades".

No estado de São Paulo, ao contrário, o juiz Luís Felipe Ferrari Bedendi, da $5^{\text {a Vara }}$ de Fazenda Pública, suspendeu a ordem de reintegração de posse de duas escolas estaduais ocupadas. Ali, o tribunal de justiça entendeu que o objetivo das ocupações não era tomar posse do prédio público, mas promover um diálogo com o Estado.

Para além dessas decisões dos órgãos judiciais para com os jovens secundaristas, os entrevistados informaram que foram autuados com processos judiciais em relação a danos públicos ocorridos durante as reintegrações de posse das escolas. Entretanto, mesmo com o governo e a mídia criminalizando o movimento estudantil, desmoralizando e desfavorecendo os acontecimentos nas escolas públicas ocupadas, a população local foi afetada e isso gerou um contra-discurso. As mães, os professores, os ativistas colaboradores e os moradores dos bairros das escolas foram sensibilizados pelas ações promovidas por esses jovens.

O que se constata é a ocorrência de um processo de formação em que os adultos aprendem com os saberes dos jovens. Na verdade, o saber era construído coletivamente dentro da ausência de hierarquias intergeracionais. E, nesse sentido, tais movimentos se colocaram de forma contrária às formas tradicionais de aprendizado, cujas instituições, famílias, escolas e igrejas transmitem conhecimento numa relação de cima para baixo. Os jovens apresentaram a perspectiva de que para discutir e fazer política não é necessário ser ou estar habilitado para tanto. E indicam em seus relatos que grande parte dos adultos ali presentes ouviram e compreenderam as demandas juvenis, assim como as problematizações das medidas de contenção de gastos públicos no Brasil.

Ao fim das ocupações, em meados de 2016, a oficialização da implementação da PEC $n^{\circ} 241$ e seus devidos encaminhamentos tiveram diferentes resultados. Nesse aspecto, os jovens apontam que, se por um lado, houve um resultado de acúmulo político por parte da população participante, por outro, houve uma frustração dos jovens ativistas devido a uma não continuidade dos processos iniciados nas ocupações. 
O fim das ocupações não possibilitou a continuidade de espaços e de atividades de trocas como as que foram vivenciadas. Os jovens relataram que não houve a manutenção das conversas, dos diálogos nos conflitos, das trocas de saberes e, no limite, foi colocado um fim para as possibilidades de resolução de conflitos e de espaços de encontros. Marta e Ângela comentaram sobre este ponto:

Então, depois, quando a gente saiu das escolas, todo mundo dispersou, assim, principalmente os moradores que ajudavam a gente na escola, as atividades coletivas já não tinham mais onde acontecer, sabe? A gente não tinha mais um lugar para nos encontrar e fazer mobilização. $O$ movimento dissolveu, mesmo entre a gente, as alunas. $E$ teve gente que ficou mal com isso, porque acreditou mesmo nas mudanças, eu mesma fiquei.

É que a gente fez tanta coisa dentro das escolas e isso se perdeu depois que as ocupações acabaram. Você vê, até as hortas que fizemos, a galera não cuidou, morreu tudo. Eu não sei dizer o que aconteceu. Acabou tão rápido quanto começou e a gente não tava preparada para isso.

Com o término das ocupações, houve um silenciamento entre os participantes e a comunidade, o que levou ao adoecimento ${ }^{10}$ de alguns jovens participantes.

Segundo eles, os encontros e $\operatorname{congressos}^{11}$ que ocorreram pós-ocupações não deram conta das demandas e das angústias dos ativistas. Os entrevistados apontam que isso ocorreu por conta do formato desses encontros e também por vícios dos próprios coletivos que carregavam resquícios partidários e hierárquicos incompatíveis com a nova lógica de atuação dos estudantes. E isso se deu também porque a realização desses eventos foi a partir dos grupos e dos espaços institucionalizados. Saulo explica que:

A gente chegou para discutir os resultados das ocupações nas escolas e os andamentos que rolariam a partir dai, né? Depois que acabou as ocupações, mas aí o povo que tava lá na direção e tal era tudo partidário, ai não teve conversa, porque as ocupações foram feitas na

\footnotetext{
${ }^{10}$ Essa questão do adoecimento foi problematizada pelos cinco jovens entrevistados, assim como foi tema levantado por jovens palestrantes presente no II Simpósio Nacional sobre Juventude, que ocorreu em Belo Horizonte, Minas Gerais, em janeiro de 2018.

${ }^{11} \mathrm{O} 42^{\circ}$ Congresso da UBEs, ocorrido em Goiânia, é um exemplo desses encontros de tomadas de decisão.
} 
horizontalidade, aí chega lá para discutir fica aquele papo de partido. Era na horizontalidade que funcionava, aí não tinha porque participar, ali era outro movimento.

O espaço coletivo construído pelos jovens nas ocupações findou abruptamente e nada foi colocado no seu lugar. O desgaste mental e físico desses jovens transparece nos aspectos subjetivos e também é resultado das experiências vividas nas ocupações com as quais a sociedade, aparentemente, não conseguiu lidar de forma construtiva. Além disso, a pouca preocupação com esses indivíduos os afetou de maneira substancial e, consequentemente, a sua perspectiva de continuidade de ações em prol da busca por melhorias na qualidade do ensino, dos espaços públicos, dos ambientes coletivos, de diálogo e de construção coletiva. Além de evidenciar o quanto nós, adultos, historicamente, temos poucas condições e percepções para lidar com a juventude.

\section{Considerações finais}

As ocupações das escolas públicas apontam para um processo contínuo de ativismo e que em determinados períodos históricos ficam mais em evidência do que em outros, levando em consideração o contexto que o país passava naquele momento. Percebe-se também que a forma de atuação da juventude mudou consideravelmente nas últimas décadas, trazendo ineditismo em práticas e envolvimento que merecem ser observados com atenção. Foi a partir das ocupações que os jovens puderam questionar conflitos de relações geracionais, hierárquicas e socialmente pré-estabelecidas, demonstrando outras formas de reivindicar mudanças a serem experimentadas.

Nessa perspectiva, desde muito antes da Revolta da Catraca (quando afirmavam que não se tratava apenas dos vinte centavos de aumento da tarifa do transporte público), a mobilização desses jovens nas ocupações perpassa pela negação aos acordos em favor dos mecanismos puramente econômicos, afirmando que o que estava em disputa não era somente o direito à escola pública e de qualidade. Sendo assim, os secundaristas com a iniciativa de ocupar escolas e fazerem delas um espaço de politização, reinventam uma outra forma de fazer política e de protagonismo juvenil. 0 
que em certa medida influenciou a participação da comunidade local e promoveu diálogos e convivências inéditas em se tratando do uso, do compartilhamento e da apropriação do espaço público urbano.

As ocupações nas escolas públicas apontaram que a entrada do jovem e da comunidade em geral na vida pública e na participação política pode ser feita a partir de novas formas de diálogos, o que, em certa medida, leva ao questionamento da função das instituições na contemporaneidade e coloca em xeque a tal racionalidade e "maturidade" da vida adulta.

Agradecimentos. O presente trabalho foi realizado com apoio da Coordenação de Aperfeiçoamento de Pessoal de Nível Superior - Brasil (CAPES) - Código de Financiamento 001. 


\section{Referências}

BONI, Valdete; QUARESMA, Sílvia Jurema. Aprendendo a entrevistar: como fazer entrevistas em ciências sociais. Em Tese, Florianópolis, v. 2, n. 1, p. 68-80, jan.2005. Disponível em: <https://periodicos.ufsc.br/index.php/emtese/article/view/18027/16976>. Acesso em: 28 jun. 2018.

BOURDIEU, Pierre. A "juventude" é apenas uma palavra. In: BOURDIEU, Pierre. Questões de sociologia. Rio de Janeiro: Marco Zero. 2003. P. 112-121.

BOURDIEU, Pierre. Condição de classe e Posição de classe. In: BOURDIEU, Pierre. A economia das trocas simbólicas, São Paulo: Perspectiva, Editora, 2013.

CALDEIRA, Teresa Pires do Rio. Qual a novidade dos rolezinhos? espaço público, desigualdade e mudança em São Paulo. Novos estud. - CEBRAP [online]. n.98, p.13-20, 2014. Disponível em: <http://dx.doi.org/10.1590/S0101-33002014000100002>. Acesso em: 28 jun. 2018.

FOOT-WHITE, Willian. Sociedade de esquina. Rio de Janeiro: Zahar, 2005.

GROPPO, L. A. A ação dos grupos juvenis. In: GROPPO, L. A. Juventude: ensaios sobre sociologia e história das juventudes modernas. Rio de Janeiro: DIFEL, 2000.

GROPPO, L. A. Sociologia da Juventude. In: GROPPO, L. A. Juventudes: sociologia, cultura e movimentos. Alfenas (MG): Unifal, 2016.

GROPPO, L. A. Introdução à sociologia da juventude. In: GROPPO, L. A. Jundiaí: Paco editorial. 2017.

HARVEY, D.“O direito à cidade”.Rev. Lutas Sociais, n² 29. São Paulo, jul./dez. 2012. p.

73-89. Traduzido do original em inglês "The right to the city", por Jair Pinheiro.

FFC/UNESP. Disponível em: <https://revistas.pucsp.br/index.php/ls/article/view/18497>. Acesso em: 28 jun. 2018.

IANNI, O. O jovem radical. In: BRITO, Sulamita de (Org). Sociologia da Juventude I. Da Europa de Marx à América Latina de hoje. Rio de Janeiro: Zahar, 1968, pg. 225-242.

LEFEBVRE, H. O direito à cidade. São Paulo: Centauro, 2001.

PAIS, J.M. A construção sociológica da juventude: alguns contributos. Análise Social, v. XXV, n.105-106, p.139-165, 1. ${ }^{\circ}$, $2 .^{\circ}$ semestre, 1990.

PARSONS, Talcot. A classe como sistema social. In: BRITO, Sulamita de (Org.). Sociologia da Juventude. Vol III. Rio de Janeiro: Zahar, 1968, pg. 47-76. 
SOUZA, Marcelo Lopes de. A prisão e a ágora: reflexões em torno da democratização do planejamento e da gestão das cidades. Rio de Janeiro: Bertrand Brasil, 2006.

TRASHER, Frederic Mílton. The gang: a study of 1313 gangs in Chicago. In: BURGESS, Ernest W.; BOGUE, Donald J. (orgs). Contributions to urban Sociology. Chicago: University of Chicago Press, 1964. Cap.42, p. 655-662.

Recebido em: 28/03/2018 Aprovado 11/07/2018

Universidade do Estado de Santa Catarina - UDESC Centro de Ciências Humanas e da Educação - FAED

Revista PerCursos Volume 19 - Número 40 - Ano 2018 revistapercursos@gmail.com 